\title{
EFFECTS OF PLANT-DERIVED SMOKE ON SEED GERMINATION OF SPECIES COMMON IN SUBTROPICAL CHINA
}

\author{
LIANG, Q. ${ }^{1,2,3}-$ DENG, H. P. ${ }^{3}-$ HE, P. ${ }^{3 *}-$ FANG, W. ${ }^{4}-$ JiANG, H. ${ }^{1}-$ LUO, T. $^{5}$

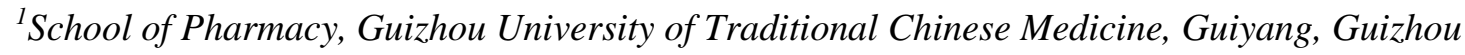 \\ 550025, PR China \\ ${ }^{2}$ School of Ecological Engineering, Guizhou University of Engineering Science, Bijie, Guizhou \\ 551700, PR China
}

${ }^{3}$ Chongqing Key Laboratory of Plant Resource Conservation and Germplasm Innovation, Institute of Resources Botany, School of Life Sciences, Southwest University, Chongqing, 400715, PR China.
${ }^{4}$ Chongqing Management Center for conversion of cropland to forest, Chongqing 400036, PR China

${ }^{5}$ College of Landscape Architecture and Life Science, Institute of Special Plants, Chongqing University of Arts and Sciences, Chongqing 402168, PR China

\author{
*Corresponding author \\ e-mail: lqin0857@qq.com
}

(Received 22 ${ }^{\text {nd }}$ Dec 2019; accepted 6 ${ }^{\text {th }}$ May 2020)

\begin{abstract}
Wildfires are predicted to increase with global climate change. Despite studies in several regions of the world indicating that burning smoke produced by wildfires may affect seed germination of some plants, little attention has been paid to this effect on wild plants in subtropical areas of China. In this study, seeds of 11 species from the Karst area of Guizhou province in China were collected for analysis. These seeds were treated with different concentrations of a plant-derived smoke solution prior to investigate seed germination parameters. We report that seven species out of the 11 tested germinated successfully, including five species which showed a positive germination response. Interestingly, we found that the seed germination percentage for Pyracantha fortuneana (Firethorn) and Osbeckia opipara seeds increased by $150 \%$ and $171 \%$ respectively following treatment with optimal smoke solution concentrations. However, smoke solution treatment had an inhibitory effect on the seed germination of one species and seed germination of one other species was unaffected by smoke solution exposure. Four species failed to germinate under our experimental conditions.
\end{abstract}

Keywords: fire, smoke aqueous, prescribed burning, forest management, vegetation regeneration

\section{Introduction}

Forest fire is one of the major causes of forest disturbance throughout the world. Due to climate change, the warmer, drier and more variable climate conditions predicted for the near future may further increase fire risk either in quantity or intensity. The recent wildfires all over the world have confirmed this prediction, such as Australia, Amazon region, California, and China. At the same time, prescribed burning is gradually recognized as an effective measure to reduce wildfire risk (Wang et al., 2019), and it has been promoted in many countries and regions. Prescribed burning refers to burning the accumulated fuels in the specified forest area within the specified time by 
controlling the fire intensity. With the increase of wildfire and prescribed burning by human, the importance of fire ecology research is further enhanced.

It is well known that the seedling regeneration for many plants is closely related to fire disturbance (Keeley and Pausas, 2018; Alahakoon et al., 2020): high temperature, burning smoke and coke are all produced by fire and can influence seed germination with variable effect sizes. Previously published studies describing the effects of plantderived smoke on seed germination are gathering increasing attention from ecologists and physiologists all over the world, particularly in recent years (Flematti et al., 2004, 2011; Keeley et al., 2018; De Lange et al., 2018; Riveiro et al., 2019). Of particular interest is the discovery that the seed germination of many plants native to regions around the world can be induced by exposure to smoke solution, including many species the seed germination of which is difficult to induce under normal conditions or whose seeds are in a dormant phase (Flematti et al., 2011; Cédric Leperlier et al., 2018). The research carried out to date in this field has enhanced the application of plantderived smoke in commercial or industrial settings. And the potential stimulatory effect of plant-derived smoke on seed germination has been widely recognized in some countries and regions (Kulkarni, et al., 2011). Plant smoke has become one of the most important tools in the field of fire ecology because the smoke produced by burning plant matter from wildfire can promote or inhibit the germination of seeds. Indeed, the concept of "plant-derived smoke ecology" has recently been discussed (Light, 2016), and the study of the ecological effects of plant-derived smoke is becoming a distinct and independent discipline. However, seed germination of some plant seeds is inhibited following exposure to high concentrations of smoke solution (Dixon et al., 1995; Zirondi et al., 2019).

At present, the germination response of seeds from 120 families and 1335 plants from around the world have been tested through stimulation by aqueous solutions of smoke or aerosol smoke, and many of them have been found to respond positively (Çatav et al., 2014; Light, 2016; Cembrowska-Lech and Kępczyński, 2017). These plants are denoted smoke responsive plants. According to the reports, smoke responsive plants research originate from South Africa (De lange et al., 2018), then many in the Mediterranean-climate ecosystems (Keeley and Fotheringham, 1998; Moreira et al., 2010; Çatav et al., 2014), and then expanded to many types of ecosystems around the world. However, few studies have focused on the effects of smoke on plant regeneration in subtropical ecosystems, including subtropical areas of China.

Based on the records of smoke-stimulated seed germination in many species from different areas, we hypothesized that smoke would enhance seed germination of species in subtropical areas of China. To test this hypothesis, we performed a seed germination experiment with seeds of eleven species growing in natural subtropical areas of China. The seed germination percentage and seed germination rate of each species were assessed in smoke solution treatments at different concentrations, and these results were compared to the controls to determine if smoke treatments resulted in any increment in seed germination percentage and rate. In parallel, we examined the percentage and rate of seed germination between species within the same family, to determine if the germination response of seeds to smoke solution is dependent on the genera and families of species. By conducting this experiment, we aimed to clarify the role of smoke in seed germination of species in subtropical areas of China. 


\section{Materials and methods}

\section{Study area and sites}

The research area is located in Bijie, a city of Guizhou province $\left(26^{\circ} 21^{\prime} \sim 27^{\circ} 46^{\prime} \mathrm{N}\right.$; $103^{\circ} 36^{\prime} \sim 106^{\circ} 43^{\prime} \mathrm{E}$ ). The total area of the city is $26,900 \mathrm{~km}^{2}, 79.31 \%$ of the total area is Karst area, and the area of rocky desertification is $24.36 \%$. This area belongs to the humid monsoon climate zone in the middle subtropical zone. The mean annual temperature in this area is $12.5^{\circ} \mathrm{C}$ and the annual mean precipitation is about $1000 \mathrm{~mm}$ with clearly defined dry and wet seasons. The precipitation is mainly concentrated in summer. Most of the vegetation in this area has degenerated into herbaceous communities and rattan thorn bush, including species of Pyracantha fortuneana (Firethorn), Cotoneaster glaucophyllus, Rosa rubus (Mayberry), Deyeuxia arundinacea, Bidens pilosa, Galinsoga parviflora and so on. Karst is widespread in this area and the soil is very dry. Plants here are suffering from the stresses of both drought and cold in the winter. During this period, vegetation above ground mostly dies off and fell on the ground, causing the accumulation of fuel, which may increase wildfire risk. Between the years of 2005 and 2009, a county of Bijie named Qi Xingguan was exposed to 102-237 wildfires every year. After that, a large number of human and financial resources have been invested in this area, accompanied by special wildfire control laws (Ruan et al., 2015). In recent years, the trend of aggravation of wildfires predicted by theory in this area has been changed, and the number of wildfires decreased significantly, but still occur every year.

\section{Seed collection}

Based on the dominance of species in the study area, we collected seeds of 11 species which growing in fire-prone areas in November 2013, from the typical Karst mountainous area of Bijie: P. fortuneana, C. glaucophyllus, Osbeckia opipara, Vernonia saligna, Spiraea japonica, B. pilosa, Carpesium cernuum, Imperata koenigii (Cogongrass), $R$. rubus, Cotoneaster adpressus, Clematis lasiandra. The characterizations of the species seeds are as follows (Table 1). These plants are common and widely distributed in the subtropical areas of China. The seeds collected were taken back to the laboratory for air drying about four weeks. Healthy seeds free of pathology and pathogens were selected, packed in paper bags and stored at room temperature.

\section{Preparation of plant-derived smoke solution}

We used smoke solution throughout this study since the concentrations can be strictly controlled compared to aerosol smoke. And smoke solution and aerosol have similar effects on seed germination according to the study of Çatav et al. (2014). On the other hand, Studies have shown that the content of smoke is consistent regardless of the kind of plants that are burned (Brown and Van Staden, 1997; Çatav, et al., 2012). We therefore used the leaves of $D$. arundinacea as the raw material to produce smoke, which is widely distributed in the Guizhou area and would therefore be representative of a wildfire in the area.

Following the methods of Coons et al. (2014), we collected D. arundinacea leaves, then cut them and incubate in an oven at $105^{\circ} \mathrm{C}$ for $5 \mathrm{~min}$, and then at $70{ }^{\circ} \mathrm{C}$ to constant weight. $100 \mathrm{~g}$ of dried leaves were then moved to a smoker, ignited, and left to produce smoke. Smoke was guided into a chamber containing $500 \mathrm{ml}$ distilled water through the pipe. This infusion was then diluted to six different concentrations (1:1000, 1:500, $1: 100,1: 50,1: 2,1: 1)(\mathrm{v}: \mathrm{v})$ before treating the seeds. 
Table 1. Description of seed characterization

\begin{tabular}{|c|c|c|c|c|c|c|c|}
\hline Species name & Family name & $\begin{array}{l}\text { Genus } \\
\text { name }\end{array}$ & $\begin{array}{l}\text { Life } \\
\text { form }\end{array}$ & Fruit type & $\begin{array}{c}\text { Seed } \\
\text { length } \\
(\mathrm{mm}) \\
\end{array}$ & \begin{tabular}{|c|} 
Seed \\
width \\
$(\mathbf{m m})$
\end{tabular} & $\begin{array}{l}\text { Seed } \\
\text { mass } \\
(\mathrm{mg})\end{array}$ \\
\hline Pyracantha fortuneana & Rosaceae & Pyracantha & Shrub & Pome & 2.48 & 1.31 & 1.39 \\
\hline Cotoneaster glaucophyllus & Rosaceae & Cotoneastr & Shrub & Pome & 4.33 & 3.18 & 10.29 \\
\hline Osbeckia opipara & Melastomataceae & Osbeckia & Shrub & Capsule & 0.43 & 0.45 & 0.05 \\
\hline Vernonia saligna & Compositae & Vernonia & Shrub & Achene & 2.19 & 0.23 & 0.17 \\
\hline Spiraea japonica & Rosaceae & Spiraea & Shrub & Follicle & 1.23 & 0.34 & 0.12 \\
\hline Bidens pilosa & Compositae & Bidens & Herb & Achene & 8.72 & 0.57 & 1.45 \\
\hline Carpesium cernuum & Compositae & Carpesium & Herb & Achene & 3.56 & 0.60 & 0.49 \\
\hline Imperata koenigii & Gramineae & Imperata & Herb & Caryopsis & 1.44 & 0.57 & 0.36 \\
\hline Rosa rubus & Rosaceae & Rubus & Shrub & Aggregate fruit & 4.56 & 2.62 & 8.46 \\
\hline Cotoneaster adpressus & Rosaceae & Cotoneaster & Shrub & Pome & 3.86 & 2.84 & 8.39 \\
\hline Clematis lasiandra & Ranunculaceae & Clematis & Liana & Achene & 3.73 & 1.73 & 2.68 \\
\hline
\end{tabular}

\section{Seed germination test}

We selected approximately 900 seeds with no obvious diseases or infection with insect pests for each species. Seeds were sterilized for $10 \mathrm{~min}$ with $1 \%$ sodium hypochlorite solution. Floating seeds were removed at this stage. After sterilization, sedimented seeds were washed three times and dried by airing. Seeds were placed in beakers at a concentration of 100 seeds per beaker, and then soaked in sterile water (ck) or at different concentrations of smoke solution. After $24 \mathrm{~h}$, seeds were leached and moved to $10 \mathrm{~cm}$ Petri dishes. Two layers of filter paper were positioned at the bottom of each dish, then four milliliters of sterile water or smoke solution was added, and this was incubated at $(25 \pm 2){ }^{\circ} \mathrm{C} 12 \mathrm{~h} /(15 \pm 2){ }^{\circ} \mathrm{C} 12 \mathrm{~h}$ in darkness. Seeds were only exposed to light briefly during the monitoring periods. Incubation was performed under dark conditions to ensure consistent conditions between treatments. A total of seven treatments were set up including the control (ck). Each treatment was performed with four replicates of 25 seeds. The seeds were monitored for germination daily. Filter paper was moistened with distilled water or smoke solution respectively if necessary, to prevent dry conditions. Seeds were considered as germinated if they had a radicle emergence $>1 \mathrm{~mm}$.

\section{Statistical analysis}

Seed germination percentage (GP) and seed germination rate (GR) were calculated for each species and treatment as follows:

$$
\begin{gathered}
G P(\%)=\left(\sum_{i=1}^{n} n_{i}\right) / N \times 100 \\
G R=\left(\sum_{i=1}^{n} n_{i}\right) / t_{i} \times 100
\end{gathered}
$$


where $\mathrm{n}_{\mathrm{i}}$ is the number of seeds which germinate on a given day, $\mathrm{N}$ is the total number of seeds sown, and $t_{i}$ is the number of days from sowing to the termination of the experiment for each species. GR represents the grains of germinated seeds per 100 days.

SPSS 20 statistical software was used for statistical analysis. The seed germination percentage and germination rate of different treatments was analyzed by one-way ANOVA (One-Way ANOVA), the significance of differences were compared by Duncan's multiple comparison $(\mathrm{a}=0.05)$.

\section{Results}

\section{Seed germination percentage}

Germination was successful following smoke exposure for seeds from 7 plant species (P. fortuneana, C. glaucophyllus, O. opipara, C. cernuum, B. pilosa, V. saligna and $I$. koenigii) out of 11 tested species (Fig. 1). In addition to C. glaucophyllus, seed germination of six additional germinated species was significantly affected by treatment with smoke solution, but the influence was not consistent between species.

There were five species belonged to Rosaceae out of a total of 11 tested species: $P$. fortuneana, $C$. glaucophyllus, S. japonica, $C$. adpressus and $R$. rubus. Only $P$. fortuneana and $C$. glaucophyllus germinated successfully from this genus. The seed germination percentage of $P$. fortuneana was $150 \%$ higher than control following smoke solution treatment at the 1:1000 dilution, but no significant differences were observed between the control treatment and higher smoke solution concentrations. For C. glaucophyllus, the seed germination percentage were unaffected by the presence of smoke solution at any concentration, compared with the control group.

Three species of Compositae plants were included in this study: C. cernuum, $B$. pilosa and $V$. saligna. Seeds of all three species germinated successfully, but the germination response was not consistent between smoke solution treatments. Smoke solution stimulated the seed germination of C. cernuum and B. pilosa. Germination of these seeds was enhanced by smoke solution at one or more of the concentrations tested. In contrast, the seed germination percentage of $V$. saligna was inhibited by smoke solution. We observed a general trend where there was an inverse correlation between smoke concentration and the seed germination percentage. At the maximum smoke solution concentration, the seed germination percentage of $V$. saligna was reduced by $70 \%$ compared to the control treatment.

Smoke solution can also promote the seed germination percentage of O. opipara and I. koenigii, both of these species' seeds showed a positive correlation with smoke solution concentration. At the maximum smoke solution concentration, the seed germination percentage was enhanced by $21.66 \%$ and $171.23 \%$ respectively. O. opipara was more sensitive to smoke solution treatment than $I$. koenigii, as an increased seed germination percentage was observed at lower smoke solution concentrations than $I$. koenigii. The seed germination percentage of $O$. opipara is significantly higher than that of control in all smoke solution concentrations tested.

\section{Seed germination rate}

In control treated samples, the seed germination rate of I. koenigii and C. cernuum is relatively high (up to 135 grains/100d), compared to the seed germination rate of others 
(Fig. 2). In addition to C. glaucophyllus, smoke solution had a significant influence on the germination rate of seeds $(\mathrm{P}<0.05)$.
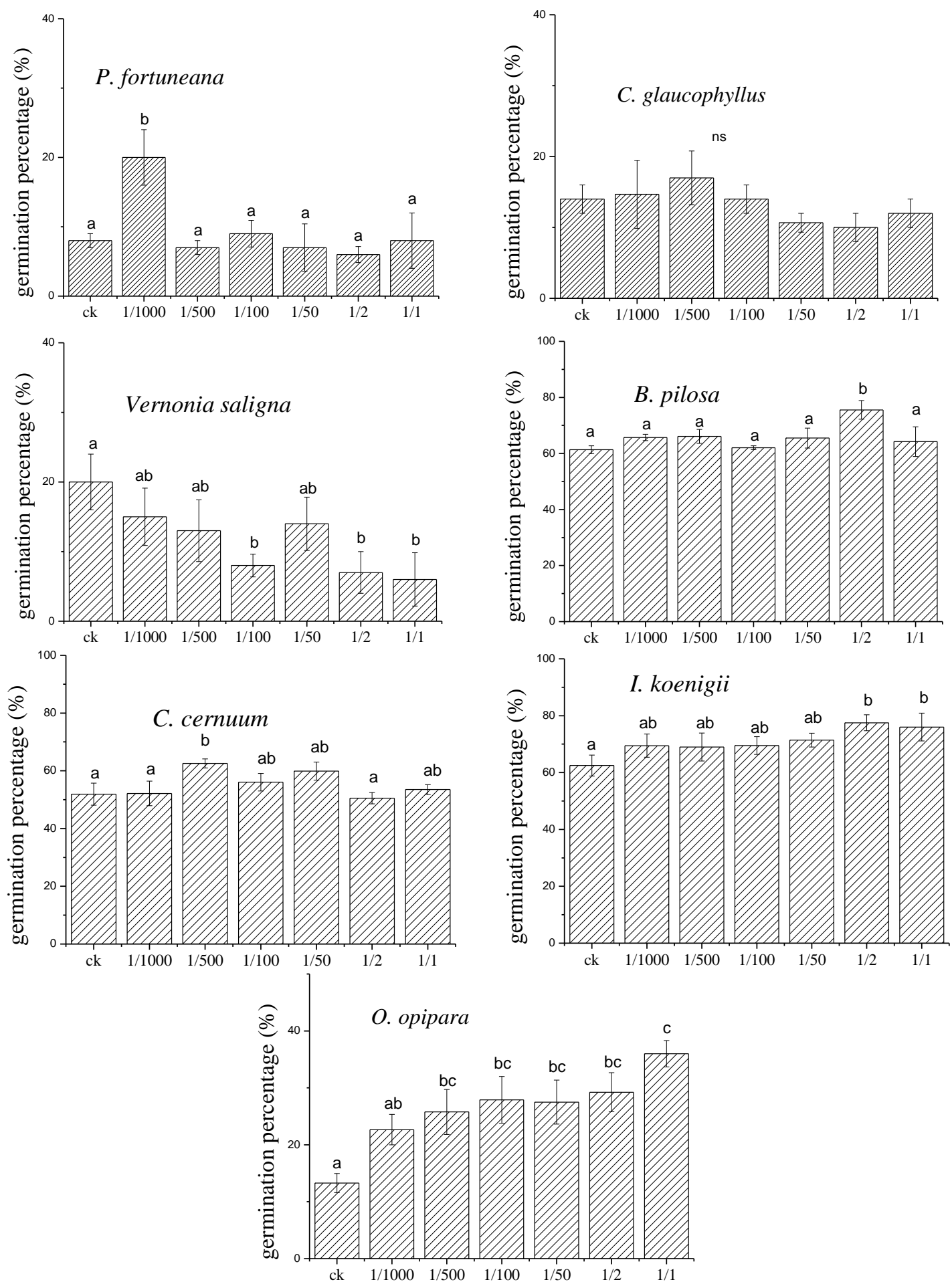

Figure 1. Seed germination percentage under different smoke solution treatment (means + s.e., $n=4)$. The same letter represents no significant difference between the groups. Different letters represent a significant difference between groups $(P<0.05)$. ck, control; 1/1000, 1/500, 1/100, $1 / 50,1 / 2,1 / 1$ represent the concentration of smoke solution $(v / v)$. (The same applies below in

Fig. 2) 

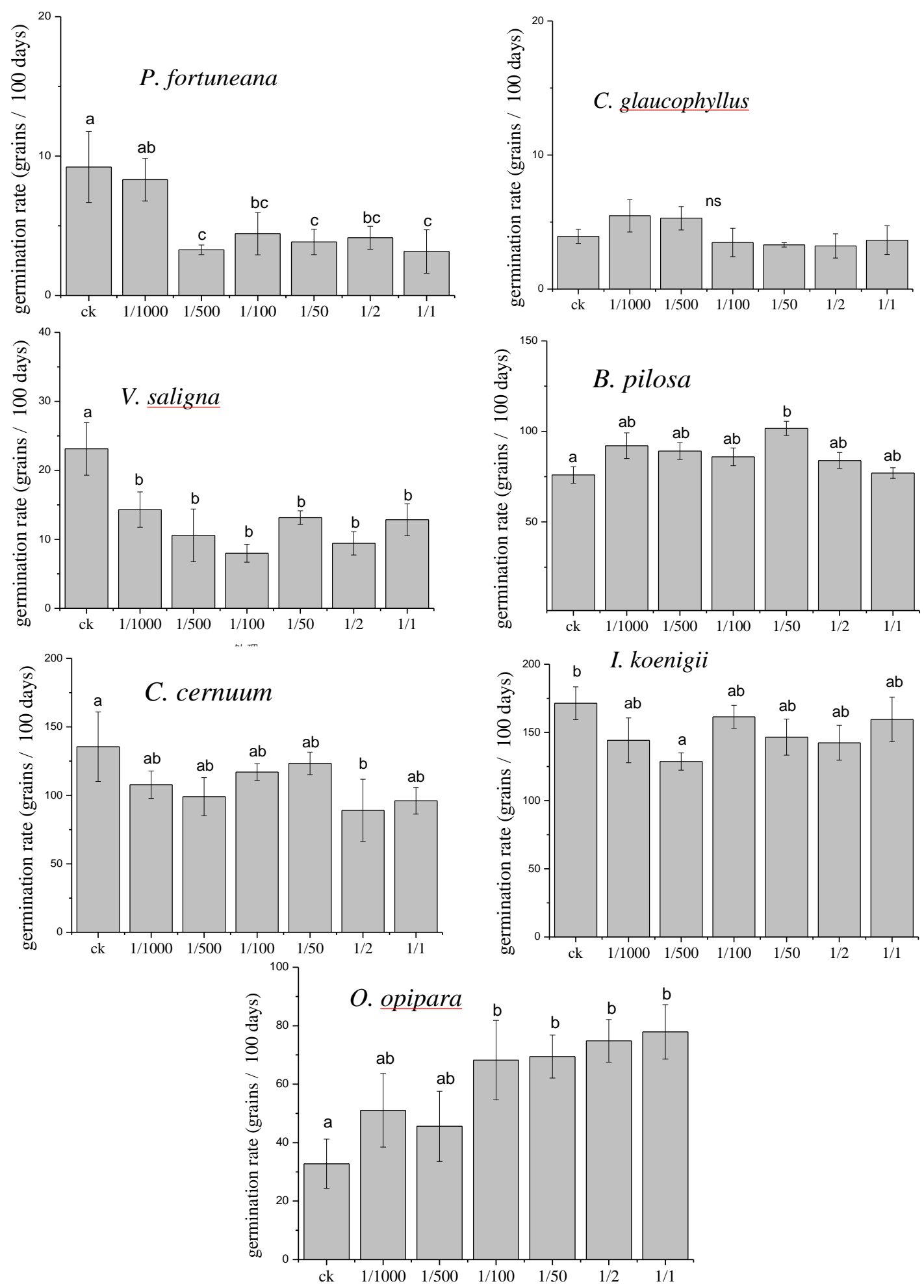

Figure 2. Seed germination rate under different smoke solution treatment (means \pm s.e., $n=4$ )

The seed germination rate of $P$. fortuneana decreased significantly when the smoke solution concentration was higher than 1:500. However, smoke solution did not affect the seed germination rate of $C$. glaucophyllus significantly, even though they were belonging to the same family (Rosaceae). The seed germination rate of Compositae 
plant $V$. saligna and $C$. cernuum were negatively correlated with the smoke solution concentration, and the seed germination rate of $B$. pilosa improved under smoke solution treatment. The seed germination rate of $I$. koenigi was significantly slower than control at a smoke solution concentration of 1:500. The seed germination rate for $O$. opipara seeds was accelerated significantly when the smoke solution concentration was equal to or greater than 1:100. When the smoke solution concentration reached 1:1, the seed germination rate peaked at approximately $137 \%$ of the control seeds.

\section{Discussion}

There were seven species out of a total of 11 tested species germinated successfully under our experimental conditions. This study is the first to report the seed germination response of the six plant species following smoke solution treatment (Except for $B$. pilosa). This study shows that, as in Mediterranean climate zones, plant-derived smoke also promotes seed germination of plants widely distributed in the subtropical humid monsoon climate area of China. In this study, most germinated species (5/7) showed enhanced seed germination under smoke solution treatment, with a wide variety of plant characteristics for example life type and fruit type. The effects on seed germination were dependent upon the concentration of smoke solution and the species tested. This result is consistent with previous research, which showed plant-derived smoke generally stimulates seed germination, but the sensitivity of plants to smoke can vary (Çatav et al., 2014; Alahakoon et al., 2020).

This study shows that plant-derived smoke solution may promote seed germination for plants widely distributed in the subtropical areas of China, but this effect is independent of the species' family and genera. Researchers found that species even belonging to the same family (Ferraz et al., 2013; Çatav et al., 2018) or generus (Kulkarni et al., 2007) also responded differently to plant-derived smoke. This study is in keeping with this work: the smoke response of plants belonging to same family differed between the Rosaceae plants $P$. fortuneana and C. glaucophyllus, as well as with the Compositae plants V. saligna and C. cernuum. Based on seed germination response to smoke solution, the plants tested here can be divided into three types (Table 2): Type A, positive responders; Type B, neutral responders; Type $\mathrm{C}$, negative responders. Type A plants are characterized by the positive response of seed germination with at least one concentration of smoke solution. These plants include $O$. opipara, I. koenigii, P. fortuneana, B. pilosa and C. cernuum. Type B plants, such as $C$. glaucophyllus, were not sensitive to smoke solution. Type $\mathrm{C}$ plants were characterized by negative response of seed germination to at least one concentration of smoke solution. Type C plants included V. saligna. The result is consistent with the study of Ferraz et al. (2013), in which the seed germination response of woody plants from the Amazon to smoke solution were studied. Overall, there are more A-type plants in the tested species, but there are other response types of plants, so further research is still needed to reveal the impact of smoke water on vegetation regeneration in the fire prone areas.

Although smoke solution treatment increased seed germination percentages in most species tested, the response of seed germination rate differed between species. Under smoke solution treatment, the seed germination rate of only $2 / 7$ species accelerated significantly, but $4 / 7$ species were slowed. smoke solution was able to increase the seed germination rate of $O$. opipara significantly, and the effect showed a positive 
correlation with the concentration of smoke solution. Seed germination rates of $V$. saligna were significantly inhibited by smoke solution. It is generally believed that the earlier germinating species in the open field will have advantages in community competition, because they have more resources, indicating that the smoke generated by wildfire may change the competition of communities.

Table 2. Response types of seed germination under smoke solution

\begin{tabular}{c|c|c|c|c|c|c|c}
\hline \multirow{2}{*}{ Treatments } & \multicolumn{5}{|c|}{ Type A } & Type B & Type C \\
\cline { 2 - 7 } & $\begin{array}{c}\boldsymbol{O} . \\
\text { opipara }\end{array}$ & $\begin{array}{c}\boldsymbol{I} . \\
\text { koenigii }\end{array}$ & $\begin{array}{c}\boldsymbol{P} . \\
\text { fortuneana }\end{array}$ & $\begin{array}{c}\boldsymbol{B} . \\
\text { pilosa }\end{array}$ & $\begin{array}{c}\boldsymbol{C} . \\
\text { cernuum }\end{array}$ & $\begin{array}{c}\boldsymbol{C} . \\
\text { glaucophyllus }\end{array}$ & $\begin{array}{c}\boldsymbol{V} . \\
\text { saligna }\end{array}$ \\
\hline $1 / 1000$ & 0 & 0 & + & 0 & 0 & 0 & 0 \\
$1 / 500$ & + & 0 & 0 & 0 & + & 0 & 0 \\
$1 / 100$ & + & 0 & 0 & 0 & 0 & 0 & - \\
$1 / 50$ & + & 0 & 0 & 0 & 0 & 0 & 0 \\
$1 / 2$ & + & + & 0 & + & 0 & 0 & - \\
$1 / 1$ & + & + & 0 & 0 & 0 & 0 & - \\
\hline
\end{tabular}

"+" indicates a positive response, seed germination percentage increased significantly under smoke solution treatment. "-" indicates a negative response, seed germination percentage decreased significantly under smoke solution treatment; "0" shows seed germination rate did not differ significantly from the control seeds with smoke solution treatment

Our results show that there are three types of responses to plant smoke, and these responses are independent with the phylogenetical family of the species. Considering that the seed germination promoting effect of smoke has no obvious regularity, the seed germination of some weeds and exotic species with low economic value but high reproductive ability may be promoted. Thus, we must remain alert to the risk that plantderived smoke generated from frequent wildfires could potentially increase weed and exotic species invasion (Mojzes and Kalapos, 2014; Alahakoon et al., 2020). Conversely, most of the tested plants are medicinal plants, garden plants or forage grasses, and it is of great value to use plant-derived smoke to improve their seed germination. In addition, the positive effect on seed germination of plant-derived smoke is of great significance. It can be used in horticulture and agriculture, and even in weeds control (by increasing the germination percentage of weeds and reducing the seed bank of weeds). Our result suggests that the plant-derived smoke can improve the species germination, thus, it can also be used as an important tool for the protection and restoration of plant communities, such as ecological restoration of mining wasteland, restoration and reconstruction of disturbed ecosystems amongst other possibilities.

Prescribed burning technologies are increasingly used in forest management in domestic and international settings. The use of prescribed fire will inevitably produce a large volume of smoke, and we cannot control the boundary and direction of the smoke just as the time and area. We do not know which species might be exposed to the smoke, nor do we know which species will be stimulated by the smoke. Thus, it is suggested that prescribed burning techniques should be used carefully before we understand the response of non - economic plants and non - target plants (such as invasive alien species) to fire and its related factors by strict control experiments. 


\section{Conclusion}

Plant-derived smoke can promote seed germination of several species of plants in subtropical areas of China, with few plants being insensitive to plant-derived smoke and others being inhibited by plant-derived smoke. Plant-derived smoke has different effects on seed germination of different plants and the differences are independent of family or generus. Therefore, burning smoke generated with wildfire is likely to change the subsequent recovery and species composition of burned areas. Because plant-derived smoke has different ecological effects on plants, it is necessary to evaluate the feasibility and efficacy of prescribed burning technology for the perspective of burning smoke in specific regions. Globally, wildfires are increasing, and fire products associated with wildfires increasing, therefore we must be aware of the effects of smoke produced with wildfires. And we suggest that future research could consider the following aspects:

a) Study the effect of plant-derived smoke on the growth of medicinal plants, ornamental plants and vegetation restoration plants, and to make full use of the advantages of smoking.

b) Study the germination response of dominant species or key species (such as endangered species, economic species and other target species) to plant-derived smoke and explore the impact of wildfire on the vegetation succession and community composition in fire prone area or prescribed burning area.

c) Study the response of high-risk invasive plants to plant-derived smoke in the fire prone region or prescribed burning areas, to prevent fire smoke from becoming an assistant of invasive plants.

d) The bioactive components in plant-derived smoke and its mechanisms have always been the concern of ecologists and chemists, which also needs further study.

Acknowledgments. This study was funded by the science and technology cooperation plan project of Guizhou Science and Technology Agency and Bijie Bureau of Science and Technology and Guizhou University of Engineering Science (No. Qiankehe LH zi [2017]7020). And supported by the top talents project of Guizhou Education Department (No. [2016]101), and the Science and Technology project of Guizhou Province (No. [2017] 7004) also.

\section{REFERENCES}

[1] Alahakoon, A. A. C. B., Perera, G. A. D., Merritt, D. J., Turner, S. R., Gama-Arachchige, N. S. (2020): Species-specific smoke effects on seed germination of plants from different habitats from Sri Lanka. - Flora 263: 151530.

[2] Brown, N. A. C., Van Staden, J. (1997): Smoke as a germination cue: a review. - Plant growth regulation 22: 115-124.

[3] Çatav, Ş. S., Bekar, İ., Ateş, B. S., Ergan, G., B., Oymak, F., Ülker, E. D., Tavşanoğlu, Ç. (2012): Germination response of five eastern Mediterranean woody species to smoke solutions derived from various plants. - Turkish Journal of Botany 36: 480-487.

[4] Çatav, Ş. S., Küçükakyüz, K., Akbaş, K., Tavşanoğlu, Ç. (2014): Smoke-enhanced seed germination in Mediterranean Lamiaceae. - Seed Science Research 24: 257-264.

[5] Çatav, Ş. S., Küc ,ükakyüz, K., Tavşanoğlu, C., Pausas, J. G. (2018): Effect of firederived chemicals on germination and seedling growth in Mediterranean plant species. Basic and Applied Ecology 30: 65-75. 
[6] Cembrowska -Lech, D., Kępczyński, J. (2017): Plant-derived smoke induced activity of amylases, DNA replication and $\beta$-tubulin accumulation before radicle protrusion of dormant Avena fatua L. caryopses. - Acta Physiologiae Plantarum 39(1): 39-39.

[7] Coons, J., Coutant, N., Lawrence, B., Finn, D., Finn, S. (2014): An effective system to produce smoke solutions from dried plant tissue for seed germination studies. Applications in plant sciences 2(3): 1-5.

[8] De Lange, J. H., Brown, N. A. C., Van Staden, J. (2018): Perspectives on the contributions by South African researchers in igniting global research on smokestimulated seed germination. - South African Journal of Botany 115: 219-222.

[9] Dixon, K. W., Roche, S., Pate, J. S. (1995): The promotive effect of smoke derived from burnt native vegetation on seed germination of Western Australian plants. - Oecologia 101(2): 185-192.

[10] Ferraz, I. D. K., Arruda, Y. M. B. C., Van Staden, J. (2013): Smoke-water effect on the germination of Amazonian tree species. - South African Journal of Botany 87: 122-128.

[11] Flematti, G. R., Ghisalberti, E. L., Dixon, K. W., Trengove, R. D. A. (2004): Compound from smoke that promotes seed germination. - Science 305(5686): 977-977.

[12] Flematti, G. R., Merritt, D. J., Piggott, M. J., Trengove, R. D., Smith, S. M., Dixon, K. W., Ghisalberti, E. L. (2011): Burning vegetation produces cyanohydrins that liberate cyanide and stimulate seed germination. - Nature Communications 2(1): 1-6.

[13] Keeley, J. E., Fotheringham, C. J. (1998): Smoke-induced seed germination in California chaparral. - Ecology 79: 2320-2336.

[14] Keeley, J. E., Pausas, J. G. (2018): Evolution of 'smoke' induced seed germination in pyroendemic plants. - South African Journal of Botany 115: 251-255.

[15] Kulkarni, M. G., Sparg, S. G., Van Staden, J. (2007): Germination and post-germination response of Acacia seeds to smoke-water and butenolide, a smoke-derived compound. Journal of Arid Environments 69: 177-187.

[16] Kulkarni, M. G., Light, M. E., Van Staden, J. (2011): Plant-derived smoke: Old technology with possibilities for economic applications in agriculture and horticulture. South African Journal of Botany 77(4): 972-979.

[17] Leperlier, C., Riviere, J. E., Allibert, A., Dessauw, D., Lacroix, S., Fock-Bastide, I. (2018): Overcoming dormancy and light requirements in seeds of Heteropogon contortus, a target species for savanna restoration. - Ecological Engineering 122: 10-15.

[18] Light, M. E. (2016): Ecology of plant-derived smoke: its use in seed germination. African Journal of Range \& Forage Science 33: 76-76.

[19] Mojzes, A., Kalapos, T. (2014): Plant-derived smoke stimulates germination of four herbaceous species common in temperate regions of Europe. - Plant Ecology 215: 411415.

[20] Moreira, B., Tormo, J., Estrelles, E., Pausas, J. G. (2010): Disentangling the role of heat and smoke as germination cues in Mediterranean Basin flora. - Annals of Botany 105: 627-635.

[21] Riveiro, S. F., García-Duro, J., Cruz, Ó., Casal, M., Reyes, O. (2019): Fire effects on germination response of the native species Daucus carota and the invasive alien species Helichrysum foetidum and Oenothera glazioviana. - Global Ecology and Conservation 20: 1-7.

[22] Ruan, P. L., Tang, T., Zhang, H. A. (2015): Study on the forest fire prevention in Bijjie experimental area of Guizhou Province. - Guizhou Forestry Science and Technology 43(2): 43-47.

[23] Wang, X. L., Xu, J. Y., Wu, Z. S., Shen, Y. C., Cai, Y. J. (2019): Effect of annual prescribed burning of wetlands on soil organic carbon fractions: A 5-year study in Poyang, China. - Ecological Engineering 138: 219-226.

[24] Zirondi, H. L., Silveira, F. A. O., Fidelis, A. (2019): Fire effects on seed germination: Heat shock and smoke on permeable vs impermeable seed coats. - Flora 253: 98-106. 